\title{
Short communication: Describing mortality and euthanasia practices on Canadian dairy farms
}

\author{
S. M. Roche, ${ }^{1,2} \odot$ R. Genore, ${ }^{1} \odot$ D. L. Renaud, ${ }^{1,2} \odot$ D. A. Shock, ${ }^{1} \oplus$ C. Bauman, ${ }^{2} \oplus$ S. Croyle, ${ }^{2} \oplus$ \\ H. W. Barkema, ${ }^{3}$ (D) J. Dubuc, ${ }^{4}$ (D) G. P. Keefe, ${ }^{5}$ (i) and D. F. Kelton ${ }^{2 *}$ (D) \\ ${ }^{1}$ ACER Consulting Ltd., Guelph, ON, Canada, N1G 5L3 \\ ${ }^{2}$ Department of Population Medicine, University of Guelph, Guelph, ON, Canada, N1G 2W1 \\ ${ }^{3}$ Department of Production Animal Health, University of Calgary, Calgary, AB, Canada, T2N 1N4 \\ ${ }^{4}$ Faculté de Médecine Vétérinaire, Université de Montréal, St-Hyacinthe, QC, Canada, J2S 2M2 \\ ${ }^{5}$ Department of Health Management, University of Prince Edward Island, Charlottetown, PE, Canada, C1A 4P3
}

\begin{abstract}
The objective of this study was to describe mortality rates and euthanasia practices used for cows, heifer calves, and male dairy calves on Canadian dairy farms. An internet survey was administered to Canadian dairy producers between March and April 2015 to collect information on current management practices. Approximately $81 \%(867 / 1,076)$ and $63 \%(673 / 1,065)$ of respondents reported that at least one animal died unassisted and at least one animal was euthanized on the farm in the preceding 12-mo period, respectively. Overall, mean mortality was $8 \%$ for cows, and 6 and $2 \%$ for preweaning and weaned heifers, respectively. On average, 48,76 , and $89 \%$ of all reported mortality events in cows, weaned heifers, and preweaning heifers were recorded as unassisted deaths. Cows that died without assistance were necropsied more often than preweaning heifers dying without assistance; these cows were also necropsied more than cows that were euthanized. Conversely, preweaning heifers that were euthanized were necropsied more frequently than those that died without assistance. Choosing not to perform necropsies on animals that die of unknown causes could represent a missed opportunity to identify cause of death and inform changes to prevent future deaths. The use of a firearm was the most common method for euthanizing cows and heifers (54\%) and male dairy calves (51\%). Approximately $7 \%$ of respondents reported using blunt force to euthanize animals. The use of this method was much higher for euthanasia of male dairy calves (34\%) than for heifer calves (7\%). Québec respondents euthanized their animals using blunt force more often than farmers from other regions. Further, 53\% of respon-
\end{abstract}

Received September 17, 2019.

Accepted December 18, 2019.

*Corresponding author: dkelton@uoguelph.ca dents using blunt force indicated it was their primary method of calf euthanasia; these results are extremely concerning. Approximately $31 \%$ of respondents who reported that they do not use blunt force to euthanize heifers and cows did report using blunt force to euthanize male dairy calves. These results can be used to inform veterinarian-client communication, broader extension tools and programs, and industry policies to improve dairy cattle health and welfare, a goal that is becoming of increasing importance from a consumer assurance perspective.

Key words: euthanasia, mortality, welfare, dairy producer practices

\section{Short Communication}

Morbidity and mortality are important health and welfare concerns for the dairy industry. In Canada, there are few nationally representative estimates of mortality. Thomsen and Houe (2006) conducted a review of 19 studies exploring cow mortality rates, reporting that the most common range for mortality was between 1 and $5 \%$. In the United States, it is estimated that 6 , 6 , and $2 \%$ of preweaning heifers, cows, and weaned heifers died (unassisted or euthanized) on US dairy farms in 2013 (USDA-APHIS, 2015). A recent review from Compton et al. (2017) suggests that the annual incidence risk and incidence density of cow mortality has increased steadily and substantially over the last 2 decades. Further, the magnitude of these concerns has grown in recent years due to increased public scrutiny of food-animal production, particularly with respect to animal welfare and youngstock management (von Keyserlingk et al., 2013; Ventura et al., 2016; Weary and von Keyserlingk, 2017). Therefore, it is important to better understand these levels affecting the dairy industry in Canada.

Cattle with untreatable conditions, not responding to treatment, or not fit for transport must be euthanized 
promptly to minimize animal suffering (NFACC, 2009). The efficacy of euthanasia methods (e.g., gun, penetrating captive bolt, injection with barbiturates) have been well researched (Turner and Doonan, 2010; Leary et al., 2013; Shearer, 2018). These results have informed recommendations in the Canadian Code of Practice for the Care and Handling of Dairy Cattle (NFACC, 2009) and are incorporated into the Dairy Farmers of Canada's dairy quality assurance program, the proAction Initiative (DFC, 2017). However, accepted methods for euthanasia are not always performed (Renaud et al., 2017). The timing of euthanasia decisions is also of critical importance. The USDA-APHIS (2015) study reported that most deaths in heifer calves (90\%) and cows $(60 \%)$ were unassisted. Similarly, high numbers of unassisted deaths in adult cows have been reported in Denmark (42\%; Thomsen et al., 2004) and Sweden (30\%; Alvåsen et al., 2014). It makes sense that animal suffering could be prevented by more expedient intervention. Further, the conduct of a thorough necropsy is reportedly uncommon, with only $22 \%$ of cows and $11 \%$ of heifer calves being necropsied in the USDA-APHIS (2015) study; more necropsies could help minimize future losses (McConnel et al., 2009; Thomsen et al., 2012).

The objective of this study was to describe the selfreported mortality rates and euthanasia practices used for cows, heifer calves, and male dairy calves on Canadian dairy farms. This project was part of a larger multi-institutional study, the Canadian National Dairy Study (NDS), conducted in collaboration with investigators at 4 Canadian veterinary colleges. Research ethics approval was received from the University of Calgary (Calgary, AB, Canada; REB no. 14-2481), University of Guelph (Guelph, ON, Canada; REB no. 14DC025), Université de Montréal (Montréal, QC, Canada; 15-007-CERES-D), and University of Prince Edward Island (Charlottetown, PE, Canada; REB no. 6006095).

An internet survey was administered to Canadian dairy producers between March and April 2015 to collect information on current management practices on their farms. Bauman et al. (2016) and Belage et al. (2017) provide detailed descriptions of the survey design and administration. Briefly, the survey was created to understand key management and disease priorities based on a previously conducted industry needs assessment (Bauman et al., 2016). The final bilingual (English and French) survey consisted of 192 questions, which were divided into sections on producer and farm demographics, biosecurity practices, disease prevalence, calf health, animal welfare, lameness, milking hygiene, reproduction, and internet and social media use. The full survey is available online (http://www .nationaldairystudy.ca/s/NDS-Survey-English.pdf). A recruitment letter outlining the scope and objectives of the study was mailed to every licensed dairy producer in Canada through their provincial milk organization. Reminders to complete the survey were posted on organizational websites and social media such as Facebook and Twitter. The survey could be completed online (Qualtrics; https://www.qualtrics.com/), on a paper copy, or by telephone. Paper questionnaires and telephone interviews were entered manually into Qualtrics.

Data from the survey were downloaded from the survey software (Qualtrics), imported, and cleaned in an Excel (2019; Microsoft Corp., Redmond, WA) spreadsheet. The cleaned data set was then imported into STATA IC16 (2013; StataCorp LP, College Station, TX) for analysis. Descriptive analyses were performed on all quantitative variables. The primary outcome variables of interest included self-reported number of unassisted deaths of cows and heifer calves (weaned and preweaning) on the farm in the past $12 \mathrm{mo}$; proportion of those animals that died of unknown causes; proportion of those that were necropsied; number of cows, heifer calves, and male dairy calves that were euthanized in the past year; proportion that were euthanized for unknown reasons; proportion of those that were necropsied; and methods of euthanasia used on cows, heifers, and male dairy calves (farm employee by firearm, blunt force trauma, captive bolt, veterinary euthanasia, deadstock employee). Farm characteristics of interest included herd size $(<50,50-150,>150$ lactating cows) and region: Western Canada (British Columbia, Alberta, Saskatchewan, Manitoba), Ontario, Québec, and Atlantic Canada (New Brunswick, Nova Scotia, Prince Edward Island, Newfoundland and Labrador).

Descriptive statistics were produced for all primary outcome variables, and farm characteristics were descriptively analyzed. Univariate analyses were conducted using statistical tests to detect differences between each primary outcome variable and farm characteristics of interest, with a $P$-value of $<0.05$ considered significant. Continuous outcome variables were evaluated against each independent farm characteristic using a one-way analysis of covariance (ANCOVA) test, with herd size added in as a covariate. A chi-squared $\left(\chi^{2}\right)$ test was used for categorical outcome variables if each cell in the contingency table had a value $>5$; otherwise, a 2-sided Fisher's exact test was used.

A total of 1,373 Canadian dairy producers responded to the survey; approximately $87 \%$ (1,202), $9 \%$ (119), and $4 \%$ (52) responses were completed online, on paper, and over the phone, respectively. This corresponds to a response rate of $12 \%$ of the Canadian dairy farm 
population. A total of 297 respondents were removed from the analysis because they either reported milking $<10$ cows or did not provide information on the number of lactating cows in their herd. The resulting 1,076 respondents ( $78 \%$ of respondents) were included for analysis. Calf mortality questions had the lowest response rate of all questions in the survey, with 314 respondents $(29 \%)$ choosing not to answer this section. Another 182 respondents were removed from the analysis, as they reported zero unassisted deaths and euthanasia for calves in all age categories, and this was considered unlikely; no significant demographic or herd-level differences between these respondents and the remaining respondents were observed. This left 578 respondents with useable data for preweaning heifer mortality and 580 respondents for weaned heifer mortality (Winder et al., 2018). As respondents were permitted to skip any questions they wished, frequency counts were lower for certain questions.

Approximately $81 \%(867 / 1,076)$ of respondents reported that at least one animal died unassisted on the farm in the past 12 -mo period. The majority of respondents $(86 \% ; 741 / 867)$ reported at least one unassisted cow death in 2014. Among those respondents with useable data on heifer calves, $92 \%(531 / 578)$ and $57 \%(329 / 580)$ reported having at least one preweaning calf and weaned calf die on the farm, respectively. Approximately $63 \%(673 / 1,065)$ of respondents reported that at least one animal was euthanized on the farm in the past 12-mo period. Most of these respondents (91\%; $589 / 644$ ) reported euthanizing at least one cow on the farm in the past year. Among those respondents with useable data on heifer calves, 29\% (110/376) and $25 \%$ $(122 / 482)$ reported euthanizing at least one weaned and one preweaning calf in 2014, respectively. Five percent of respondents $(49 / 1,076)$ reported euthanizing at least one male dairy calf in 2014 .

The average herd size was 83 milking cows (range $=$ 10 to 1,037). Mean cow mortality (unassisted and euthanized) in the previous 12 -mo period was $6.8(\mathrm{SD}=$ 7.6), which is approximately $8 \%$ (number of cattle dying in the past $12 \mathrm{mo} /$ total herd size) of the herd. Mean mortality for preweaning and weaned heifer calves was $1.6(\mathrm{SD}=5.8 ; \sim 2 \%$ all weaned heifers) and 3.8 (SD $=6.6 ; \sim 6 \%$ of all preweaning heifers), respectively. On average, 48,76 , and $89 \%$ of all reported mortality events in cows, weaned heifers, and preweaning heifers were recorded as unassisted deaths, respectively. Table 1 presents farm mortality information for each group of animals. These results are comparable to published reports from the United States, particularly with respect to calf mortality $(6 \%$ in preweaning heifers and $2 \%$ in weaned heifers; USDA-APHIS, 2015). Few studies regarding calf mortality are available; however, Mee (2008) and Compton et al. (2017) both report an increasing risk of perinatal mortality on dairy farms. The proportions of deaths that were unassisted among weaned and preweaning heifers (76 and $89 \%$, respectively) in this study were comparable to that reported in the United States (89 and 94\%, respectively; USDA-APHIS, 2015). Collectively, these studies highlight that the highest risk for calf mortality is during the preweaning period, and most of these deaths are unassisted. Although cow mortality estimates in this study were higher (9\% vs. $6 \%$ ), the proportion of unassisted cow mortality was similar, accounting for 52 and $60 \%$ of all cow deaths in the NDS and US studies, respectively (USDA-APHIS, 2015). The proportion of unassisted cow deaths reported in this study are similar to those reported in Denmark (42\%; Thomsen et al., 2004) and higher than those reported in Sweden (30\%; Alvåsen et al., 2014). High rates of mortality (assisted or unassisted) may be indicative of poor animal welfare on the farm (Thomsen and Houe, 2006; Uetake, 2013; Mee, 2013). Given the high proportion of unassisted mortality, these findings also suggest that many animals may have compromised welfare before death that could have been addressed earlier. More research is needed to explore these results in detail. More importantly, these results support the need for more extension efforts focusing on improvements in calf health and euthanasia decisions.

Overall, the average proportion of animals necropsied was low. A one-way ANCOVA test with herd as a fixed effect showed that cows that died without assistance were reported to be necropsied more often than preweaning heifers that died without assistance (11\% vs. $5 \% ; F=41.4, P=0.04)$. Similarly, cows that died without assistance were necropsied more frequently than cows that were euthanized $(31 \%$ vs. $8 \% ; F=6.3$, $P=0.03)$. Conversely, preweaning heifers that were euthanized were necropsied more frequently than those that died without assistance $(15 \%$ vs. $4 \% ; F=10.7, P$ $=0.02)$. The USDA-APHIS (2015) study reported that necropsies were performed on $22 \%$ of cows and $11 \%$ of heifer calves. Although those data are not stratified by method of death (unassisted vs. euthanasia), the proportion of cows and heifers necropsied was twice that of estimates in the present study. Establishing cause of death through routine necropsy would help producers and their veterinarians understand health challenges on the farm (McConnel et al., 2009). In fact, Thomsen et al. (2012) demonstrated that farm treatment records, farmer opinion on cause of death, and results from necropsy rarely align, and even when they 
do, necropsy adds significant information to what was already known. Necropsies therefore allow for a better understanding of farm mortality and offer an opportunity to develop tailored preventative recommendations to minimize future losses.

Dairy producers in Western Canada conducted necropsies on their cows ( $41 \%$ of all deaths) more frequently than producers in Ontario (13\%), Atlantic Canada $(12 \%)$, or Québec $(10 \%)\left(\chi^{2}=147.1, P<0.01\right)$. Western Canadian producers also conducted necropsies on preweaning dairy heifers that died of unknown causes more frequently than did Québec producers (15\% vs. $\left.3 \% ; \chi^{2}=52.8, P=0.02\right)$. These differences may be the result of bovine veterinarians in Western Canada compared with other regions more strongly advocating for necropsy. Compared with veterinarians in other regions of the country, many Western Canadian bovine veterinarians have more experience working with large beef feedlots that use necropsies as part of a feedlot health program (Wildman et al., 2000; Gaudet, 2015). These regional differences might also be confounded by herd size. Although herd size was not significant in this analysis, we hypothesize that producers with larger herds might be more motivated to investigate mortality. Furthermore, herd size differences were observed in the United States, with larger farms performing necropsies more often (USDA-APHIS, 2015). Larger farms may be more likely to have standardized protocols and keep more detailed records, which would prompt these actions. The consequences of disease in a larger herd can also be greater (i.e., more cattle at risk $=$ greater absolute economic losses) and the economics of the operation might more readily allow for a veterinarian to perform necropsies or they may have the staff to conduct necropsies themselves.

The use of a firearm was the most commonly reported method for euthanizing cows and heifers (54\%; $351 / 633)$ and male dairy calves $(51 \%$; $24 / 47$; Figure 1 ). Similar findings have been reported in the United States (Fulwider et al., 2008). The use of a firearm is one of the acceptable methods for the euthanasia of cattle in the Canadian Code of Practice (NFACC, 2009). In this study, significant differences were observed between the number and type of methods used, region, and herd size. Approximately $80 \%$ (513/639) of respondents reported using only one method; another $19 \%(121 / 639)$ reported the use of 2 methods. Québec farms reported using only one method for on-farm euthanasia more often than farms from Western Canada $\left(86 \%\right.$ vs. $73 \%$; $\chi^{2}$ $=10.6, P<0.01)$ and Ontario $\left(86 \%\right.$ vs. $78 \% ; \chi^{2}=10.6$, $P=0.03)$. Among those that reported using 2 methods, the most common combination of methods was the use of a gun and having a veterinarian perform euthanasia, with $68 \%(83 / 122)$ reporting these 2 together.

Western Canadian (68\%), Ontario (68\%), and Atlantic Canadian (67\%) producers reported euthanizing their animals using a gun more often than Québec producers $\left(30 \% ; \chi^{2}=82.3, P<0.01\right)$. Québec producers reported having a veterinarian euthanize their animals more frequently than Western Canadian and Ontario producers ( $51 \%$ vs. $28 \%$; $\chi^{2}=16.2, P<0.01$ ). Veterinary fees are subsidized by the provincial government in Québec, which might make Québec farmers more likely to rely on their veterinarian to perform this sensitive procedure. Finally, Western Canadian farmers reported the use of captive bolts more often than did

Table 1. Self-reported mortality and euthanasia information (mean $\pm \mathrm{SD} ; \% \pm \mathrm{SD}$ in parentheses) for Canadian dairy farms that reported at least one animal dying in 2014

\begin{tabular}{|c|c|c|c|}
\hline \multirow[b]{2}{*}{ Item } & \multirow[b]{2}{*}{ Dairy cows } & \multicolumn{2}{|c|}{ Dairy heifers } \\
\hline & & Weaned & Preweaning \\
\hline Overall farm mortality (unassisted and euthanized) & $\begin{array}{c}6.8 \pm 7.6 \\
(8.2 \pm 9.2)\end{array}$ & $\begin{array}{l}1.6 \pm 5.8 \\
(2.4 \pm 4.4)^{1}\end{array}$ & $\begin{array}{c}3.8 \pm 6.6 \\
(6.4 \pm 8.3)^{1}\end{array}$ \\
\hline Unassisted deaths & $\begin{array}{c}3.6 \pm 4.4 \\
(47.6 \pm 33.2)^{\mathrm{a}}\end{array}$ & $\begin{array}{c}2.3 \pm 3.8 \\
(75.9 \pm 18.7)^{\mathrm{b}}\end{array}$ & $\begin{array}{c}4.4 \pm 6.0 \\
(88.8 \pm 16.3)^{\mathrm{b}}\end{array}$ \\
\hline Unassisted deaths due to unknown causes & $\begin{array}{c}2.2 \pm 2.3 \\
(30.6 \pm 40.2)^{\mathrm{a}}\end{array}$ & $\begin{array}{c}1.6 \pm 1.3 \\
(25.5 \pm 48.3)^{\mathrm{b}}\end{array}$ & $\begin{array}{c}2.7 \pm 2.8 \\
(22.7 \pm 39.1)^{\mathrm{b}}\end{array}$ \\
\hline Unassisted deaths necropsied & $\begin{array}{c}0.4 \pm 1.1 \\
(11.2 \pm 30.0)^{\mathrm{a}}\end{array}$ & $\begin{aligned} 0.1 & \pm 0.7 \\
(6.8 & \pm 23.1)^{\mathrm{b}}\end{aligned}$ & $\begin{array}{c}0.2 \pm 0.7 \\
(4.4 \pm 15.8)^{b}\end{array}$ \\
\hline Euthanasia due to unknown causes & $\begin{array}{c}0.5 \pm 1.7 \\
(11.6 \pm 28.7)\end{array}$ & $\begin{array}{c}0.1 \pm 0.2 \\
(10.5 \pm 29.7)\end{array}$ & $\begin{array}{c}0.1 \pm 0.5 \\
(12.1 \pm 30.3)\end{array}$ \\
\hline Euthanasia necropsied & $\begin{array}{c}0.4 \pm 1.6 \\
(8.3 \pm 25.0)^{\mathrm{a}}\end{array}$ & $\begin{array}{c}0.1 \pm 0.2 \\
(5.9 \pm 23.7)^{\mathrm{a}}\end{array}$ & $\begin{array}{c}0.1 \pm 0.5 \\
(14.7 \pm 34.3)^{b}\end{array}$ \\
\hline
\end{tabular}




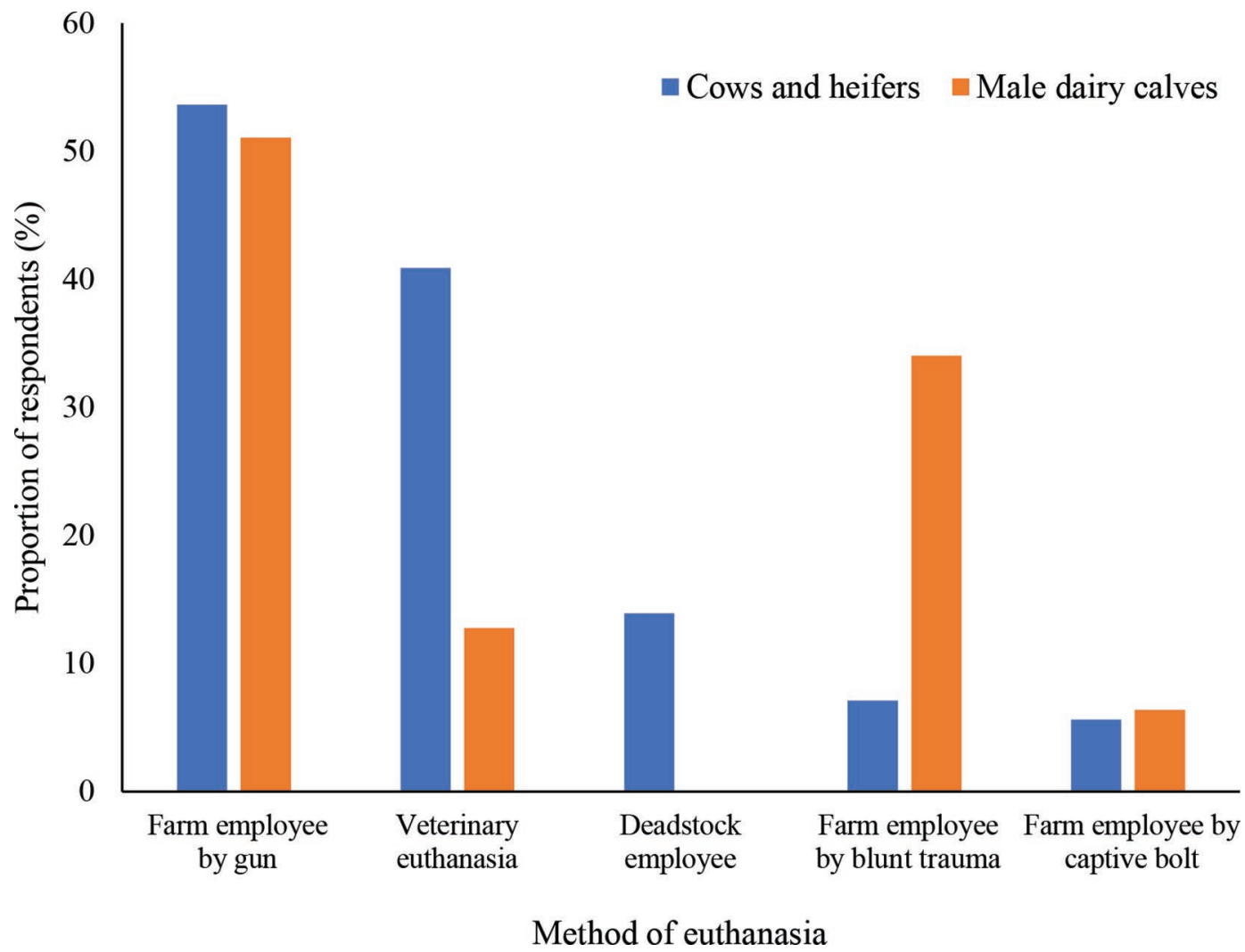

Figure 1. Proportion of respondents reporting methods of euthanasia used on farm for cows, heifers, and male dairy calves (more than one response per respondent permitted).

Ontario and Québec farmers (17\% vs. 3 and $4 \%$; $\chi^{2}=$ $30.9, P<0.01)$.

As reported by Renaud et al. (2017), 93\% of respondents in the NDS indicated that they used an acceptable method of euthanasia based on the Canadian Code of Practice (NFACC, 2009), whereas the remaining 7\% reported using blunt force. Although the number of respondents reporting on the use of methods for euthanizing male dairy calves was low $(\mathrm{n}=47)$, the use of blunt force was much higher, proportionally, for euthanasia of male dairy calves $(34 \% ; 16 / 47)$ than for heifer calves $\left(7 \%\right.$; 48/633) $\left(\chi^{2}=26.4, P<0.01\right)$. Among the 16 respondents that reported euthanizing their male dairy calves using blunt force, $72 \%$ were from Québec; significantly more than from Western Canada (0\%), Atlantic Canada (10\%), or Ontario $(18 \%)\left(\chi^{2}=14.4\right.$, $P=0.03)$. Further, $53 \%(24 / 45)$ of respondents that reported using blunt force indicated it was their primary method of calf euthanasia. These results are extremely concerning. This method of euthanasia may be ineffective at destroying brain tissue and is difficult to perform consistently (Leary et al., 2013). As such, blunt force trauma is deemed unacceptable in the Canadian Code of Practice (NFACC, 2009). When comparing use of blunt force in heifers and cows versus male dairy calves in this study, $31 \%(5 / 16)$ of respondents who reported they do not use blunt force to euthanize heifers and cows did report using blunt force to euthanize male dairy calves $\left(\chi^{2}=28.3, P<0.01\right)$. These differences are unfortunate and likely reflect the broader differences in management that have been observed between these 2 groups of calves (Renaud et al., 2017).

This study had some limitations that may affect the conclusions. The low response rates for the mortality questions ( $54 \%$ of all survey respondents responded to mortality questions) and a high number of reported zero values for calf mortality may have affected the external validity of the study. This low response and lack of consistency among respondents specifically within the mortality section of the survey may reflect a lack of understanding or knowledge, lack of willingness to share this information, or an inability to accurately answer the question (e.g., lack of accurate records). The survey responses in the NDS are also self-reported and may not necessarily reflect true practices on the farm due to socially desirable responding and incon- 
sistent question responses. The length of the survey may have contributed to respondent fatigue, which may have affected the quality of the answers or the respondents' willingness to complete all questions. The use of self-reports for mortality may also be subject to recall bias. However, the similarity of our findings with other mortality studies (Thomsen et al., 2004; Alvåsen et al., 2014; USDA-APHIS, 2015; Compton et al., 2017) suggests that these results may be reflective of the broader target population. Belage et al. (2017) have also shown that NDS survey respondents closely match the demographics of the Canadian dairy industry. The results, tests used, and differences identified in this study should be considered exploratory; further work in a Canadian context is needed on a more comprehensive data set to further substantiate these results.

In conclusion, this study provides information on cattle mortality that can be used as a metric for Canadian dairy farms. Although overall farm mortality rates are comparable to those of previous reports, the high proportion of unassisted deaths among cows and preweaning heifers represents an important animal welfare concern. Choosing not to perform necropsies on many of the animals that died of unknown causes represents an important missed opportunity to identify cause of death and inform changes to prevent future deaths. A small proportion of farms acknowledged using methods of euthanasia that are unacceptable. This represents an important animal health and welfare risk that must be addressed. These results should inform veterinarian-client communication, broader extension tools and programs, and industry policies to improve dairy cattle health.

\section{ACKNOWLEDGMENTS}

The authors thank all respondents to the $2015 \mathrm{Na}$ tional Dairy Study, which was funded by Dairy Farmers of Canada (Ottawa, ON, Canada) and Agriculture and Agri-Food Canada (Ottawa, ON, Canada) through the Dairy Research Cluster 2 Program. The authors have not stated any conflicts of interest.

\section{REFERENCES}

Alvåsen, K., P. T. Thomsen, C. H. Sandgren, M. J. Mörk, and U. Emanuelson. 2014. Risk factors for unassisted on-farm death in Swedish dairy cows. Anim. Welf. 23:63-70. https://doi.org/10 $.7120 / 09627286.23 .1 .063$

Bauman, C. A., H. W. Barkema, J. Dubuc, G. P. Keefe, and D. F. Kelton. 2016. Identifying management and disease priorities of Canadian dairy industry stakeholders. J. Dairy Sci. 99:10194-10203. https://doi.org/10.3168/jds.2016-11057.

Belage, E., S. Dufour, C. A. Bauman, A. Q. Jones-Bitton, and D. F. Kelton. 2017. The Canadian National Dairy Study 2015 - Adop- tion of milking practices in Canadian dairy herds. J. Dairy Sci 100:3839-3849. https://doi.org/10.3168/jds.2016-12187.

Compton, C. W. R., C. Heuer, P. T. Thomsen, T. E. Carpenter, C. V. C. Phyn, and S. McDougall. 2017. Invited review: A systematic literature review and meta-analysis of mortality and culling in dairy cattle. J. Dairy Sci. 100:1-16. https://doi.org/10.3168/jds .2016-11302.

Dairy Farmers of Canada (DFC). 2017. proAction animal care validation requirements. Accessed Aug. 16, 2019. https://www .dairyfarmers.ca/proaction/resources/animal-care.

Fulwider, W. K., T. Grandin, B. E. Rollin, T. E. Engle, N. L. Dalsted, and W. D. Lamm. 2008. Survey of dairy management practices on one hundred thirteen north central and northeastern United States dairies. J. Dairy Sci. 91:1686-1692. https://doi.org/10.3168/jds .2007-0631.

Gaudet, A. 2015. Roles and opportunities for technicians in digital imaging technology to perform necropsies. 48: 185-187 in Proc. Am. Assoc. Bovine Pract. Annu. Mtg., New Orleans, LA. Am. Assoc. Bovine Pract., Auburn, AL.

Leary, S., W. Underwood, and R. Anthony. 2013. AVMA Guidelines for the Euthanasia of Animals. 8th ed. American Veterinary Medical Association, Schaumburg, IL.

McConnel, C. S., F. B. Garry, J. E. Lombard, J. A. Kidd, A. E. Hill, and D. H. Gould. 2009. A necropsy-based descriptive study of dairy cow deaths on a Colorado dairy. J. Dairy Sci. 92:1954-1962. https://doi.org/10.3168/jds.2008-1505.

Mee, J. F. 2008. Prevalence and risk factors for dystocia in dairy cattle: A review. Vet. J. 176:93-101.

Mee, J. F. 2013. Why do so many calves die on modern dairy farms and what can we do about calf welfare in the future? Animals (Basel) 3:1036-1057. https://doi.org/10.3390/ani3041036.

National Farm Animal Care Council. 2009. Code of Practice for the Care and Handling of Dairy Cattle. National Farm Animal Care Council, Lacombe, AB, Canada.

Renaud, D. L., T. F. Duffield, S. J. LeBlanc, D. B. Haley, and D. F. Kelton. 2017. Management practices for male calves on Canadian dairy farms. J. Dairy Sci. 100:6862-6871. https://doi.org/10.3168/ jds.2017-12750.

Shearer, J. K. 2018. Euthanasia of cattle: Practical considerations and application. Animals (Basel) 8:57. https://doi.org/10.3390/ ani8040057.

Thomsen, P. T., K. Dahl-Pedersen, and H. E. Jensen. 2012. Necropsy as a means to gain additional information about causes of dairy cow deaths. J. Dairy Sci. 95:5798-5803. https://doi.org/10.3168/ jds.2012-5625.

Thomsen, P. T., and H. Houe. 2006. Dairy cow mortality. A review. Vet. Q. 28:122-129. https://doi.org/10.1080/01652176.2006 .9695218 .

Thomsen, P. T., A. M. Kjeldsen, J. T. Sørensen, and H. Houe. 2004. Mortality (including euthanasia) among Danish dairy cows (1990 - 2001). Prev. Vet. Med. 62:19-33. https://doi.org/10.1016/j .prevetmed.2003.09.002.

Turner, P. V., and G. Doonan. 2010. Developing on-farm euthanasia plans. Can. Vet. J. 51:1031-1034

Uetake, K. 2013. Newborn calf welfare: A review focusing on mortality rates. Anim. Sci. J. 84:101-105. https://doi.org/10.1111/asj .12019

USDA-APHIS (Animal and Plant Health Inspection Service). 2015. Dairy 2014: Health and management practices on U.S. dairy operations, 2014. USDA-APHIS National Animal Health Monitoring System. Accessed Aug. 16, 2019. https://www.aphis.usda.gov/ animal_health/nahms/dairy/downloads/dairy14/Dairy14_dr PartIII.pdf.

Ventura, B. A., M. A. G. von Keyserlingk, H. Wittman, and D. M. Weary. 2016. What difference does a visit make? Changes in animal welfare perceptions after interested citizens tour a dairy farm? PLoS One 11:e0154733. https://doi.org/10.1371/journal.pone .0154733 .

von Keyserlingk, M. A. G., N. P. Martin, E. Kebreab, K. F. Knowlton, R. J. Grant, M. Stephenson, C. J. Sniffen, J. P. Harner III, A. D 
Wright, and S. I. Smith. 2013. Invited review: Sustainability of the US dairy industry. J. Dairy Sci. 96:5405-5425. https://doi.org/10 $.3168 /$ jds.2012-6354.

Weary, D. M., and M. A. G. von Keyserlingk. 2017. Public concerns about dairy-cow welfare: How should the industry respond? Anim. Prod. Sci. 57:1201-1209. https://doi.org/10.1071/AN16680.

Wildman, B. K., O. C. Schunicht, G. K. Jim, P. T. Guichon, C. W. Booker, and R. A. Tollens. 2000. The use of computer technology to facilitate the capture of feedlot necropsy information. Can. Vet. J. 41:124-125.

Winder, C. B., C. A. Bauman, T. F. Duffield, H. W. Barkema, G. P. Keefe, J. Dubuc, F. Uehlinger, and D. F. Kelton. 2018. Canadian National Dairy Study: Heifer calf management. J. Dairy Sci. 101:10565-10579. https://doi.org/10.3168/jds.2018-14680.

\section{ORCIDS}

S. M. Roche (๑) https://orcid.org/0000-0001-6934-6497

R. Genore ๑ https://orcid.org/0000-0001-7737-6047

D. L. Renaud (으 https://orcid.org/0000-0002-3439-3987

D. A. Shock (1) https://orcid.org/0000-0003-0796-6820

C. Bauman (1) https://orcid.org/0000-0001-6706-5456

S. Croyle (ㄴ) https://orcid.org/0000-0002-1074-8114

H. W. Barkema @ https://orcid.org/0000-0002-9678-8378

J. Dubuc (1) https://orcid.org/0000-0003-1013-8372

G. P. Keefe @ https://orcid.org/0000-0003-2356-7344

D. F. Kelton ๑ https://orcid.org/0000-0001-9606-7602 